NichU

DeptE

ResSIE

$\mathrm{D}$

非262
RESEARCH SEMINAR IN INTERNATIONAL ECONOMICS

Department of Economics

The University of Michigan

Ann Arbor, Michigan 48109-1220

SEMINAR DISCUSSION PAPER NO. 262

\title{
GATT: A COOPERATIVE EQUILIBRIUM IN A NONCOOPERATIVE TRADING REGIME?
}

by

Thomas L. Hungerford

The University of Michigan

May 1990

(Revised)

I would like to thank John Chamberlin, Ted Bergstrom, Mark Bagnoli, Alan Deardorff, and seminar participants at Michigan and Wayne State for comments on earlier versions of this paper. Any remaining errors are, of course, my own.

SUMNER AND LAURA

FOSTER LIBRARY

\section{Ju $3 \mid 1900$}

THE UNIVERSITY OF MICHIGAN 



\section{GATT: A COOPERATIVE EQUILIBRIUM \\ IN A NONCOOPERATIVE TRADING REGIME?}

\section{Introduction}

Many observers of the international economy claim that the General Agreement on Tariffs and Trade (GATT) is not working - that many of the major international players are not abiding by the rules and are instead impeding trade through the use of nontariff restrictions (Stern 1987). Besides nontariff measures, many point to defects in the dispute settlement mechanism as a contributing factor to this breakdown (Jackson 1979). This paper will examine this 'breakdown' of GATT by specifically modeling the dispute settlement procedure with nontariff barriers (NTBs). It is found that the equilibrium outcome(s) involves each country imposing nontariff barriers to trade.

One well known reason to impose trade barriers is to increase welfare, and one common policy is the import tariff. The theoretical possibility of improving the terms of trade has long been recognized: if a country is a large enough buyer in world markets, it can improve its terms of trade in a monopolistic manner by imposing tariffs on imports (i.e., the optimal tariff) and thus improve welfare (Meade 1952). This gives each large country an incentive to set the optimal tariff. However improving the terms of trade in one country necessarily means a worsening of the terms of trade and declining welfare for the country's trading partners.

Since a country's trade policies have effects on other countries, we have an environment which gives rise to the possibility of strategic interaction. If one country's trade policy harms another country then the harmed country has an incentive to retaliate. Several investigators (Dixit 1987, Johnson 1954-55 and McMillan 1986) have formally analyzed this idea in static $2 \times 2$ trade models with the result that both countries levy tariffs. On the other hand, other researchers (Dixit 1987 and Jensen and Thursby 1980) have shown that cooperative behavior (free trade) is an equilibrium strategy in a dynamic non-cooperative tariff game. 
However, none of these studies explains why countries are resorting to NTBs. Deardorff (1987) reviews various reasons why NTBs are preferred to tariffs. The most compelling reason, he concludes, is the perception on the part of policy makers and their constituents that tariffs will not reduce imports. As will be seen, simply substituting NTBs in place of tariffs into a dynamic game does not change the outcome: cooperative behavior is still an equilibrium strategy. NTBs must somehow be different from tariffs in terms of how trade is restricted.

One important difference is that NTBs are not as transparent as tariffs. Some claim that NTBs are essentially invisible and can take virtually an unlimited number of forms (Economic Report of the President 1988). Since they are difficult to detect their use will not invite retaliation. Some NTBs, such as the nonenforcement of certain intellectual property right laws, were initially invisible and were discovered only after an investigation. Some domestic measures, for example health and safety rules, while visible have an ambiguous status. An investigation may be required to determine if a particular rule is a NTB or a legitimate health rule. ${ }^{1}$ In either case, once a nontariff barrier is identified it is difficult to measure its effect on trade (Deardorff and Stern 1984).

Some recent studies have incorporated NTBs into game theoretic trade models. Riezman (1987), in an infinitely repeated game with uncertainty and asymmetric information (NTBs), shows that "free trade will never occur." But Riezman's result crucially depends on countries reverting to 'reversionary' (retaliation) times even when their terms of trade improve too much. A country's terms of trade will improve for any of three reasons: (1) the country sets its own optimal trade barrier, (2) there are random economic fluctuations, and (3) the other country lowers its trade barriers below the optimum. None of these reasons provide a country with an incentive to change its trade policy to 'reversionary' times.

On the other hand, Copeland (1986), using a two-stage game with a cooperative first stage (negotiations) and a noncooperative second stage to model trade policy, demonstrates that countries will use "alternative types of barriers" (i.e., NTBs) in the second stage. But this set-up precludes the use of retaliation to enforce the spirit of the negotiated settlement from the first stage of the game. In a related paper, Copeland (1989) examined tariffs and

\footnotetext{
1 The recent EEC ban on the importation of hormone treated beef is an example. At one point the U.S. asked for a GATT panel to be set up to determine if the ban was a health regulation or a trade barrier.
} 
quotas in a game with the possibility of retaliation. One case involves the negotiated setting of tariffs but not quotas. He shows that if tariffs are "properly" set in the cooperative stage then no quota war will start in the noncooperative stage. However, Rodriguez's (1974) trade eliminating quota war will break out if the tariff negotiations break down or some other mistake occurs in the tariff negotiations. The final outcome of this case is one of extremes: no quotas or no trade.

This paper examines the problems that NTBs create for the dispute-settlement mechanism of GATT in a two country infinitely repeated game with uncertainty and asymmetric information. The next section sets up the model and examines the case where retaliation is certain when NTBs are suspected. The GATT investigation requirement of the dispute settlement procedure is added and analyzed in the third section. Concluding remarks are offered in the final section of the paper.

\section{The Game with Certainty of Retaliation}

For the purposes of this paper, the dispute settlement mechanism ${ }^{2}$ will be stripped down to its barest essential features. It will be modeled as a trigger strategy. A trigger strategy is a strategy where a player will do action $a$ if the state of the world is $A$ and will do action $b$ if the state is not $A$. Specifically, in the context of the GATT this means that a country will levy its GATT bound tariff level as long as all others do so, but should a trading partner cheat by raising its tariff or imposing some other trade barrier then the country will retaliate against its offending trading partner by increasing its tariff on imports. ${ }^{3}$

In this section, the stylized dispute-settlement mechanism will be analyzed within the context of a two-country two-good trade model. While each country has some power to affect world prices it is assumed that each industry is competitive. The use of export taxes as a way of exploiting monopoly power is ruled out. ${ }^{4}$ Since trade relations are long-lived, it is assumed that the game is infinitely played. The whole game consisting of the infinite repetitions is called a supergame, and each play of the supergame is a subgame. The payoff (or welfare level) to the supergame is the sum of payoffs of each subgame appropriately

\footnotetext{
2 The primary GATT article dealing with dispute settlement is Article XXIII.

3 In the language of the GATT this is referred to as a compensatory suspension of concessions (Dam 1970).

4 Export taxes and duties are prohibited in the U.S. by article I, section 8, clause 5 of the Constitution.
} 
discounted. In this supergame each country chooses a strategy that determines what action to take at each play of the game. These choices depend on the history of prior actions taken by each player. The present model draws on Green and Porter's (1984) analysis of cartels under price uncertainty.

Assume that each country has an indirect utility function representing consumer preferences. The indirect utility function, $U_{i}\left(p_{i}, I_{i}\right)$, is a nonincreasing function of domestic prices and a nondecreasing function of income in country $i \in\{1,2\}$. Domestic prices and income are in turn functions of country $i$ 's terms of $\operatorname{trade}^{5}, \pi_{i}$, the domestic tariff on the imported good, $\tau_{i}$, and nontariff barriers (see Copeland 1986 and Woodland 1982 for the derivation).

The set-up used here for the incorporation of NTBs has some elements in common with Copeland (1986). The first step is to determine the monetary equivalent of NTBs. Define $\rho_{i}$ as the vector of country $i$ 's policy instruments. Some of the policy instruments could have as their main purpose the limitation of imports while others may have purely domestic goals but have the effect of adversely interfering with trade. Next, let $\kappa_{i}$, the level of trade barrier resulting from $\rho_{i}$, be defined as the level of tariffs that would lead to the same reduction in imports, given world prices. In other words; it is assumea that there exists a function such that $\kappa_{i}=h\left(\rho_{i}\right.$.

Since $\kappa_{i}$ is the level of the trade barriers in tariff units induced by $\rho_{i}$ and $\tau_{i}$ is the tariff level that is included in $\rho_{i}$, the protective impact of the NTBs in the policy instrument vector (assumed to be everything but $\tau_{i}$ ) is

$$
\mu_{i}=\kappa_{i}-\tau_{i}
$$

In other words, the protective effects of NTBs are treated as residuals between tariff levels, which are negotiated at GATT sponsored Multilateral Trade Negotiations (MTNs), and the total protective impact of $\rho_{i}$. It should be noted that the protective effect of NTBs can be redundant with other NTBs or the tariff.

Import demands also depend on economic conditions. There are various random supply and demand shocks which effect the economy. Let these various shocks in each country be summarized by a single random variable, $\delta_{i}$, such that increases in $\delta_{i}$ decrease import demand in country $i$. Next, let $g\left(\delta_{1}, \delta_{2}\right)$ be the joint distribution function of the

\footnotetext{
5 A country's terms of trade is defined here as the relative world price of the imported good to the exported good.
} 
two random variables. Now each country's import demand function can be represented as $M_{i}\left(\pi_{i}, \tau_{i}, \mu_{i}, \delta_{i}\right)$. The balance of trade condition

$$
\pi_{1} M_{1}\left(\pi_{1}, \tau_{1}, \mu_{1}, \delta_{1}\right)=M_{2}\left(\pi_{2}, \tau_{2}, \mu_{2}, \delta_{2}\right)
$$

implicitly defines $\pi_{1}$ (and thus $\pi_{2}$ ) as

$$
\pi_{1}=\pi_{1}\left(\tau_{1}, \mu_{1}, \tau_{2}, \mu_{2}, \delta_{1}, \delta_{2}\right)
$$

Assuming the Marshall-Lerner condition holds and that tariff revenues and quota rents are redistributed to consumers then it is easily shown that the following set of four inequalities hold

$$
\frac{\partial \pi_{i}}{\partial \mu_{i}}<0 ; \quad \frac{\partial \pi_{i}}{\partial \delta_{i}}<0 ; \quad \frac{\partial \pi_{i}}{\partial \mu_{j}}>0 ; \quad \frac{\partial \pi_{i}}{\partial \delta_{j}}>0 .
$$

Define national income as

$$
I_{i}=G\left(p_{i}\right)+r\left(\pi_{i}, \tau_{i}, \mu_{i}\right)
$$

where $r(\cdot)$ is government revenue from the trade barriers, ${ }^{6}$ and $G\left(p_{i}\right)$ is the value of domestic output. ${ }^{7}$ Domestic prices, $q_{i}$ and $p_{i}$ (consumer and producer prices respectively), are functions of $\pi_{i}, \mu_{i}$, and $\tau_{i}$. Substituting all this into the indirect utility function yields

$$
U_{i}\left(q_{i}, G\left(p_{i}\right)+r\left(\pi_{i}, \boldsymbol{\tau}_{i}, \mu_{i}\right)\right)=H_{i}\left(\tau_{i}, \mu_{i}, \tau_{j}, \mu_{j}, \delta_{i}, \delta_{j}\right)
$$

which is assumed concave and twice continuously differentiable in $\tau_{i}$ and $\mu_{i}$. Given the derivation of $H_{i}$ the following inequalities hold

$$
\frac{\partial H_{i}}{\partial \mu_{i}}>0 ; \quad \frac{\partial H_{i}}{\partial \tau_{i}}>0 ; \quad \frac{\partial H_{i}}{\partial \delta_{i}}>0 ; \quad \frac{\partial H_{i}}{\partial \mu_{j}}<0 ; \quad \frac{\partial H_{i}}{\tau_{j}}<0 ; \quad \frac{\partial H_{i}}{\partial \delta_{j}}<0 .
$$

Since NTBs are assumed initially invisible, their effects cannot be directly observed. Therefore each country must use some observable variable as an instrument for the level of $\mu_{i}$. The most handy variable in this set-up is the terms of trade. Consequently, it is maintained in this section that a country will retaliate if its terms of trade rises (and hence

6 It is possible that $r(\cdot)$ could be negative, implying that the NTBs entail some administrative costs and generate no revenue for the government.

7 Woodland defines the GNP function and includes factor endowments as an argument. I assume, in order to keep the analysis tractable, that factor endowments are constant and therefore suppress the argument. 
worsens) above some trigger level, $\bar{\pi}_{i}$, that is if $\pi_{i}\left(\tau_{i}, \mu_{i}, \tau_{j}, \mu_{j}, \delta_{i}, \delta_{j}\right)>\bar{\pi}_{i}{ }^{8}$ Condition (1) suggests that $\pi_{i}$ could rise above the trigger for any of three reasons: (i) increases in foreign tariffs or NTBs, (ii) a rise in the foreign country's random shock term, and/or (iii) a fall in the domestic random shock term.

Define a contingent strategy for country $i$ as the infinite sequence $s_{i}=\left\{s_{i 0}, s_{i 1}, s_{i 2}, \ldots\right\}$ where $s_{i 0}$ is an initial action, and $s_{i t}$ determines $i$ 's action in period $t$ given the history of previous actions of the other player in the game (i.e., $s_{i t}=f_{i}\left(h_{0}, h_{1}, \ldots, h_{t-1}\right)$ where $h_{0}$ to $h_{t-1}$ describe what occurred in periods 0 to $t-1$ ). Each country's action in any period is an ordered pair, $s_{i t}=\left(\tau_{i}, \mu_{i}\right)$. The cooperative strategy is $s_{i}^{\times}=\left(\bar{\tau}_{i}, 0\right)$ where $\bar{\tau}_{i}$ is country $i$ 's GATT tariff binding (it could be zero if there is free trade) and the retaliation action, $\boldsymbol{s}_{\boldsymbol{i}}^{i}$, is country $i$ 's response action to country $j$ 's retaliatory tariff $\left(s_{j}^{i}\right)$ after $i$ has been suspected of imposing NTBs.

Now let $H_{i}\left(\mu_{i}\right)=E_{\delta} H_{i}\left(\bar{\tau}_{i}, \mu_{i}, \bar{\tau}_{j}, 0, \delta_{i}, \delta_{j}\right)$ be country $i$ 's single-period expected payoff from playing $\mu_{i}$ and let $H_{i}^{i}=E_{\delta} H_{i}\left(s_{i}^{i}, s_{j}^{i}, \delta_{i}, \delta_{j}\right)$ be the single-period expected payoff to country $i$ after country $j$ has retaliated by levying a compensatory tariff and country $i$ plays its best response strategy (i.e., it adjusts its level of protective effect of NTBs, perhaps even to zero). Given this set-up it is safe to assume that

$$
H_{i}\left(\mu_{i}\right)>E_{\delta} H_{i}\left(s_{i}^{*}, s_{j}^{*}, \cdot, \cdot\right)>H_{i}^{i}
$$

That is, the single period payoff to defecting is greater than the payoff to cooperating which is greater than the payoff when the other country is retaliating. ${ }^{9}$ Time periods can be categorized into two groups: "normal" periods and retaliatory periods. In retaliatory periods one country will retaliate for a past defection by the other country and the defecting country will play its best response. Normal periods are characterized by the absence of retaliation.

Let $V_{i}\left(\mu_{i}\right)$ be the expected discounted present value payoff to country $i$ if it sets its

\footnotetext{
8 Recently, Rep. Gephardt suggested that the U.S. focus on the bilateral trade deficit as an instrument for another country's use of NTBs. The assumption of balanced trade in this paper rules out the use of such an instrument.

9 This ranking is consistent with that obtained when analyzing the optimal tariff using offer curves.
} 
NTB protective level to $\mu_{i}$. Then $V_{i}\left(\mu_{i}\right)$ can be written as:

$$
V_{i}\left(\mu_{i}\right)=H_{i}\left(\mu_{i}\right)+\operatorname{Pr}\left(\pi_{j}>\bar{\pi}_{j}\right)\left\{\sum_{t=1}^{t_{i}^{*}-1} \beta_{i}^{t} H_{i}^{i}+\beta_{i}^{t_{i}^{*}} V_{i}\left(\mu_{i}\right)\right\}+\beta_{i} \operatorname{Pr}\left(\pi_{j} \leq \bar{\pi}_{j}\right) V_{i}\left(\mu_{i}\right)
$$

where $t_{i}^{*}$ is the number of retaliation periods. The payoff is the single-period gain from defecting (before the other country can react) plus the expected gains from continued defection. Country $j$ will retaliate whenever $\pi_{j}>\bar{\pi}_{j}$.

Since $\pi_{j}(\cdots)$ is a function of two random variables $\left(\delta_{1}\right.$ and $\left.\delta_{2}\right)$ it is therefore itself a random variable with distribution $F\left(\pi_{j} ; \tau_{i}, \mu_{i}, \tau_{j}, \mu_{j}\right)\left(=F\left(\pi_{j}\right)\right)$. Substituting this into equation (4) and solving for $V_{i}(\cdot)$ yields

$$
V_{i}\left(\mu_{i}\right)=\frac{H_{i}\left(\mu_{i}\right)-H_{i}^{i}}{1-\beta_{i}^{t_{i}^{t}}-F\left(\bar{\pi}_{j}\right)\left(\beta_{i}-\beta_{i}^{t_{i}^{i}}\right)}+\frac{H_{i}^{i}}{1-\beta_{i}} .
$$

This shows that the discounted present value payoff is what it would be in retaliation periods plus the single-period payoff gain to playing $\mu_{i}$ in "normal" periods, appropriately discounted.

In order to determine the optimal value of $\mu_{i}$, we need to examine the first order conditions of country $i$ 's optimization problem. The first order necessary conditions for equation (5) yields after some cancellation

$$
\begin{aligned}
V_{i}^{\prime}\left(\mu_{i}\right)= & \left(1-\beta_{i}^{t_{i}^{*}}-F\left(\bar{\pi}_{j}\right)\left(\beta_{i}-\beta_{i}^{i_{i}^{*}}\right)\right) \frac{\partial H_{i}\left(\mu_{i}\right)}{\partial \mu_{i}} \\
& +\left(\beta_{i}-\beta_{i}^{t_{i}^{*}}\right)\left(H_{i}\left(\mu_{i}\right)-H_{i}^{i}\right) \frac{\partial F\left(\bar{\pi}_{j}\right)}{\partial \mu_{i}} \\
= & 0 .
\end{aligned}
$$

That is, country $i$ will set $\mu_{i}$ at the level where the marginal gain to increasing its NTB protective level is just offset by the increase in the risk of triggering retaliation and suffering a loss.

The same condition holds for country $j$. When both of these conditions hold, it places two constraints on the equilibrium vector of NTB protective levels. This outcome demonstrates that the fact that NTBs aren't observable does not necessarily lead to each country defecting. The intuitive idea is that country $j$ punishes country $i$ 's defection by retaliating for a sufficient number of periods to wipe out the single period gain country $i$ receives from 
defecting. But this trigger mechanism has the undesirable property of having retaliatory periods when neither country has defected. Countries will have to retaliate when the random economic conditions push their terms of trade past their preset trigger in order to keep the threat of retaliation credible. Furthermore this game ignores the institutional constraint that the GATT places on the trading environment.

\section{The Game under the GATT Trading Environment}

The GATT dispute settlement mechanism requires that an investigation be conducted before countries retaliate. In addition trade laws in many countries require that an investigation be launched when trading partners are suspected of engaging in unfair trade practices. The cost of any investigation must therefore be added to the model. Let the cost incurred by country $i$ in its investigation of country $j$ 's trade practices be denoted as $b_{i}$. National income can now be rewritten as $G\left(p_{i}\right)+r\left(\pi_{i}, \tau_{i}, \mu_{i}, b_{i}\right)$. Substituting this expression into the indirect utility function yields country $i$ 's single period payoff function, $H_{i}\left(\tau_{i}, \mu_{i}, \tau_{j}, \mu_{j}, b_{i}, \delta_{i}, \delta_{j}\right)$ where

$$
\frac{\partial H_{i}}{\partial b_{i}}<0
$$

The full impact of NTBs is difficult to detect, let alone measure. Let the probability of country $j$ detecting country $i$ 's NTB after an investigation be denoted as $\gamma_{j^{\prime}}^{i}$ It is assumed to be an increasing and concave function of $\mu_{i}$ and $b_{j}$ such that

$$
0 \leq \gamma_{j}^{i}\left(b_{j}, \mu_{i}\right) \leq 1 ; \quad \gamma_{j}^{i}\left(0, \mu_{i}\right)=0 ; \quad \gamma_{j}^{i}\left(\infty, \mu_{i}\right)=1 ; \quad \gamma_{j}^{i}\left(b_{j}, 0\right)=0
$$

The following assumptions are made to facilitate the analysis:

A1. The magnitudes of $\delta_{i}$ and $\delta_{j}$ are not observed by the other country and each country may not easily observe its own random shock.

A2. The investigations are conducted instantaneously, that is, if country $i$ 's terms of trade rises above the trigger in period $t$, the results of the investigation are known by period $t+1$, and so retaliation, if warranted, begins in period $t+1$.

Now a country will launch an investigation if its terms of trade rise above some predetermined trigger, but it is quite possible that the other country's NTBs may not be detected, 
in which case "normal" times prevail. If the other country's NTBs are detected ${ }^{10}$ then the aggrieved country will retaliate.

Country $i$ 's optimal policy is to play $s_{i}^{i}$ (it's best response action) in retaliation periods after being caught defecting and $\mu_{i}$ in "normal" times. Now $V_{i}\left(\mu_{i}\right)$ has the functional form:

$$
\begin{gathered}
V_{i}\left(\mu_{i}\right)=H_{i}\left(\mu_{i}\right)+\operatorname{Pr}\left(\pi_{j}>\bar{\pi}_{j}\right)\left\{\gamma_{j}^{i}\left(b_{j}, \mu_{i}\right)\left(\sum_{t=1}^{t_{i}^{*}-1} \beta_{i}^{t} H_{i}^{i}+\beta_{i}^{t_{i}^{*}} V_{i}\left(\mu_{i}\right)\right)\right. \\
\left.+\left(1-\gamma_{j}^{i}\left(b_{j}, \mu_{i}\right)\right) \beta_{i} V_{i}\left(\mu_{i}\right)\right\}+\beta_{i} \operatorname{Pr}\left(\pi_{j} \leq \bar{\pi}_{j}\right) V_{i}\left(\mu_{i}\right) .
\end{gathered}
$$

Solving for $V_{i}(\cdot)$ yields

$$
V_{i}\left(\mu_{i}\right)=\frac{H_{i}\left(\mu_{i}\right)-H_{i}^{i}}{1-\beta_{i}+\left(1-F\left(\bar{\pi}_{j}\right)\right) \gamma_{j}^{i}\left(b_{j}, \mu_{i}\right)\left(\beta_{i}-\beta_{i}^{t_{i}^{*}}\right)}+\frac{H_{i}^{i}}{1-\beta_{i}} .
$$

Again, this shows that the discounted present value payoff is what it would be in retaliation periods plus the single-period payoff gain to playing $\mu_{i}$ in "normal" periods, appropriately discounted.

In order to determine the optimal value of $\mu_{i}$, we need to examine the first order conditions of country $i$ 's optimization problem. The first order condition of equation (9) yields the necessary condition ${ }^{11}$ :

$$
V_{i}^{\prime}\left(\mu_{i}\right)=0
$$

Again country $i$ will set $\mu_{i}$ at the level where the marginal gain to increasing its NTB protective level is just offset by the increase in the risk of getting caught and suffering a loss. Condition (10) places two rigid constraints on the equilibrium vector of NTB protective levels. Notice that the optimal $\mu_{i}$ depends on country $j$ 's effort at uncovering $i$ 's use of NTBs. It is clear that when $b_{j}=0$ country $i$ 's optimal $\mu_{i}\left(=\bar{\mu}_{i}\right)$ is greater than zero, since the first order condition evaluated at $b_{j}=0$ and $\mu_{i}=0$ is positive. It is reasonable to suppose that there exists a $b_{j}\left(=\bar{b}_{j}\right)$ large enough such that $\mu_{i}$ will equal zero. Given this the locus of points satisfying condition (10) is shown in figure 1. It is assumed that the second order conditions for a maximum hold.

The main question to be answered is: does country $j$ have an incentive to launch an investigation when its terms of trade worsen (i.e., set $\left.b_{j}>0\right)$ ? In order to examine this

\footnotetext{
10 I am assuming here that a country will not mistakenly detect NTBs that are not present.

11 The full expression is shown in the appendix.
} 
question, let $V_{j}\left(b_{j}\right)$ be country $j$ 's discounted present value payoff from cooperating and spending $b_{j}$ on trade investigations. In this case $V_{j}$ has the functional form

$$
\begin{aligned}
V_{j}\left(b_{j}\right)= & H_{\dot{v}}\left(\mu_{i}\right)+\operatorname{Pr}\left(\pi_{j}>\bar{\pi}_{j}\right) \gamma_{j}^{i}\left(b_{j}, \mu_{i}\right)\left\{\beta_{j} H_{j}^{i}\left(b_{j}\right)+\sum_{t=2}^{t_{i}^{*}-1} \beta_{j}^{t} H_{j}^{i}+\beta_{j}^{t_{i}^{*}} V_{j}\left(b_{j}\right)\right\} \\
& +\operatorname{Pr}\left(\pi_{j}>\bar{\pi}_{j}\right)\left(1-\gamma_{j}^{i}\left(b_{j}, \mu_{i}\right)\right)\left(\beta_{j} H_{j}\left(\mu_{i}, b_{j}\right)+\beta_{j}^{2} V_{j}\left(b_{j}\right)\right) \\
& +\beta_{j} \operatorname{Pr}\left(\pi_{j} \leq \bar{\pi}_{j}\right) V_{j}\left(b_{j}\right)
\end{aligned}
$$

where

$$
\begin{aligned}
H_{j}\left(\mu_{i}\right) & =E_{\delta} H_{j}\left(\bar{\tau}_{j}, 0, \bar{\tau}_{i}, \mu_{i}, 0, \delta_{i}, \delta_{j}\right), \\
H_{j}^{i} & =E_{\varepsilon} H_{j}\left(s_{j}^{i}, s_{i}^{i}, 0, \delta_{i}, \delta_{j}\right), \\
H_{j}\left(\mu_{i}, b_{j}\right) & =E_{\delta} H_{j}\left(\bar{\tau}_{j}, 0, \bar{\tau}_{i}, \mu_{i}, b_{j}, \delta_{i}, \delta_{j}\right),
\end{aligned}
$$

and

$$
H_{j}^{i}\left(b_{j}\right)=E_{\varepsilon} H_{j}\left(s_{j}^{i}, s_{i}^{i}, b_{j}, \delta_{i}, \delta_{j}\right)
$$

Some manipulation of equation (11) gives

$$
\begin{aligned}
V_{j}\left(b_{j}\right)= & \frac{H_{j}^{i}}{1-\beta_{j}} \\
& \quad-\frac{H_{j}^{i}-H_{j}\left(\mu_{i}\right)+\beta_{j}\left(1-F\left(\bar{\pi}_{j}\right)\right)\left\{H_{j}^{i}-\left(\gamma_{j}^{i} H_{j}^{i}\left(b_{j}\right)+\left(1-\gamma_{j}^{i}\right) H_{j}\left(\mu_{i}, b_{j}\right)\right)\right\}}{1-\beta_{j}\left(\beta_{j}+F\left(\bar{\pi}_{j}\right)-\beta_{j} F\left(\bar{\pi}_{j}\right)\right)+\gamma_{j}^{i}\left(1-F\left(\bar{\pi}_{j}\right)\right)\left(\beta_{j}^{2}-\beta_{j}^{t_{i}^{*}}\right)}
\end{aligned}
$$

or country $j$ 's payoff if country $i$ defects is what it would receive in retaliatory periods minus a weighted average of the difference between its single-period payoff from retaliation and the 'suckers' payoff $\left(H_{j}\left(\mu_{i}\right)\right)$ and the difference between retaliation and the expected single-period payoff from launching an investigation.

The first order condition for expression (12) yields the necessary condition for a maximum $^{12}$ with respect to $b_{j}$ :

$$
V_{j}^{\prime}\left(b_{j}\right)=0
$$

This expression gives two more constraints on the equilibrium vector. This expression is also a function of both $b_{j}$ and $\mu_{i}$. When $\mu_{i}$ equals zero the optimal value of $b_{j}$ is zero since

12 The full expression is found in the appendix. 
expression (13) is negative at $\mu_{i}=0$. The locus of points satisfying condition (13) is shown in figure 1.

The intersection of the two curves gives the equilibrium values of $b_{j}$ and $\mu_{i}{ }^{13}$ It should be noted that the equilibrium involves positive NTB levels. Furthermore, it is interesting that country $j$ does not spend enough on its investigation to guarantee that country $i$ will not erect nontariff barriers to trade.

\section{Concluding Remarks}

This paper has examined the use of nontariff barriers to trade in a two country infinitely repeated game. A country's incentive to impose trade barriers was to increase welfare (the optimal tariff argument). Therefore the results apply only to large countries. This paper differs from other investigations of NTBs in that GATT procedures on dispute settlement are incorporated into the analysis. The dispute settlement procedure is modeled as a trigger strategy.

There are two results of the paper. The first, from section 2, is that the addition of uncertainty and asymmetric information (NTBs) into a tariff game does not necessarily lead to noncooperative behavior. However, the equilibrium strategy has the undesirable property of having retaliatory periods when neither country has defected. Countries have to retaliate when random economic conditions push their terms of trade past their preset trigger in order to keep the threat of retaliation credible. The full explanation for the prevalence of NTBs among large countries must lie elsewhere.

The second and major result shows that with the addition of the investigation technology the free trade outcome is not achieved. Both countries will impose NTBs even in the face of threatened retaliation. The main reason behind this is that the risk of getting caught and the associated losses are not great enough to outweigh the gains from impeding trade. While this result agrees with both Copeland's (1986) and Riezman's (1987) results, the present model incorporates the salient features of the trading environment (i.e., the GATT). This paper has shown that there is an equilibrium (possibly multiple equilibria)

13 The slope of the locus of points satisfying condition (10) has an ambiguous sign but is continuous and connects points $\bar{b}_{j}$ and $\bar{\mu}_{i}$. This fact suggests that there may be more than one equilibrium pair. The important point, however, is that none of the equilibrium points includes $\mu_{i}=0$. 
in an infinitely repeated game with the threat of punishment but free trade (or some other negotiated tariff binding) is not the equilibrium outcome. The present results fit with reality: the record shows that today most industrialized countries impede trade with NTBs (Nogués, Olechowski and Winters 1986). 


\section{APPENDIX:}

\section{FIRST ORDER CONDITIONS}

The first order necessary condition for a maximum of expression (9) is:

$$
\begin{aligned}
V_{i}^{\prime}\left(\mu_{i}\right)= & \left(1-\beta_{i}+\left(1-F\left(\bar{\pi}_{j}\right)\right) \gamma_{j}^{i}\left(b_{j}, \mu_{i}\right)\left(\beta_{i}-\beta_{i}^{t_{i}^{*}}\right)\right) \frac{\partial H_{i}\left(\mu_{i}\right)}{\partial \mu_{i}} \\
& \quad-\left(\beta_{i}-\beta_{i}^{t_{i}^{*}}\right)\left(H_{i}\left(\mu_{i}\right)-H_{i}^{i}\right)\left(\frac{\partial \gamma_{j}^{i}}{\partial \mu_{i}}\left(1-F\left(\bar{\pi}_{j}\right)\right)-\gamma_{j}^{i}\left(b_{j}, \mu_{i}\right) \frac{\partial F\left(\bar{\pi}_{j}\right)}{\partial \mu_{i}}\right) \\
= & 0 .
\end{aligned}
$$

The first order necessary condition for a maximum of expression (12) is:

$$
\begin{aligned}
V_{j}^{\prime}\left(b_{j}\right)= & \beta_{j}\left\{\frac{\partial \gamma_{j}^{i}}{\partial b_{j}}\left(H_{j}^{i}\left(b_{j}\right)-H_{j}\left(\mu_{i}, b_{j}\right)\right)+\gamma_{j}^{i} \frac{\partial H_{j}^{i}\left(b_{j}\right)}{\partial b_{j}}+\left(1-\gamma_{j}^{i}\right) \frac{\partial H_{j}\left(\mu_{i}, b_{j}\right)}{\partial b_{j}}\right\} \\
& +Z\left(\beta_{j}^{2}-\beta_{j}^{i_{i}^{*}}\right) \frac{\partial \gamma_{j}^{i}}{\partial b_{j}} \\
= & 0
\end{aligned}
$$

where

$$
Z=\frac{H_{j}^{i}-H_{j}\left(\mu_{i}\right)+\beta_{j}\left(1-F\left(\bar{\pi}_{j}\right)\right)\left\{H_{j}^{i}-\left(\gamma_{j}^{i} H_{j}^{i}\left(b_{j}\right)+\left(1-\gamma_{j}^{i}\right) H_{j}\left(\mu_{i}, b_{j}\right)\right)\right\}}{1-\beta_{j}\left(\beta_{j}+F\left(\bar{\pi}_{j}\right)-\beta_{j} F\left(\bar{\pi}_{j}\right)\right)+\gamma_{j}^{i}\left(1-F\left(\bar{\pi}_{j}\right)\right)\left(\beta_{j}^{2}-\beta_{j}^{t_{i}^{*}}\right)}
$$




\section{Bibliography}

Copeland, Brian (1986), "Strategic Interaction Among Nations: Negotiable and Non-negotiable Trade Barriers," University of British Columbia, mimeo.

Copeland, Brian (1989), "Tariffs and Quotas: Retaliation and Negotiation with Two Instruments of Protection," Journal of International Economics, 26: 179-188.

Dam, Kenneth W. (1970), The GATT: Law and International Economic Organization, Chicago: University of Chicago Press.

Deardorff, Alan V. (1987), "Why Do Governments Prefer Nontariff Barriers?," CarnegieRochester Conference Series on Public Policy, 26.

Deardorff, Alan V. and Robert M. Stern (1984), "Methods of Measurement of Nontariff Barriers," UNCTAD/ST/MD/28, United Nations, Geneva.

Dixit, A.K. (1987), "Strategic Aspects of Trade Policy," in Advances in Economic Theory: Fifth World Congress, T.F. Bewley, ed., Cambridge: Cambridge University Press.

Green, Edward J. and Robert H. Porter (1984), "Noncooperative Collusion under Imperfect Price Information," Econometrica, 52(1): 87-100.

Jackson, John H. (1979), "Governmental Disputes in International Trade Relations: A Proposal in the Context of GATT," Journal of World Trade Law, 13(1): 1-21.

Jensen, Richard and Marie Thursby (1980) "Free Trade: Two Non-cooperative Equilibrium Approaches," Ohio State University working paper \#58.

Johnson, H.G. (1953-4), "Optimum Tariff and Retaliation," Review of Economic Studies, 55: $142-153$.

McMillan, John (1986), Game Theory in International Economics, Chur, Switzerland: Harwood Academic Publishers.

Meade, James E. (1952), A Geometry of International Trade, London: Allen and Unwin, Ltd.

Nogués, Julio J., Andrzej Olechowski and L. Alan Winters (1986), "The Extent of Nontariff Barriers to Industrial Countries' Imports," The World Bank Economic Review, 1(1): 181-199.

Riezman, Raymond (1987), "Dynamic Tariffs with Asymmetric Information," University of Iowa, mimeo.

Rodriguez, Carlos Alfredo (1974), "The Nonequivalence of Tariffs and Quotas Under Retaliation," Journal of International Economics, 4: 295-98.

Stern, Robert M. (1987), U.S. Trade Policies in a Changing World Economy, Cambridge, MA: MIT Press.

United States (1988), Economic Report of the President 1988, Washington, D.C.: GPO.

Woodland, A.D. (1982), International Trade and Resource Allocation, Amsterdam: NorthHolland. 
Figure 1 The NTB Equilibrium

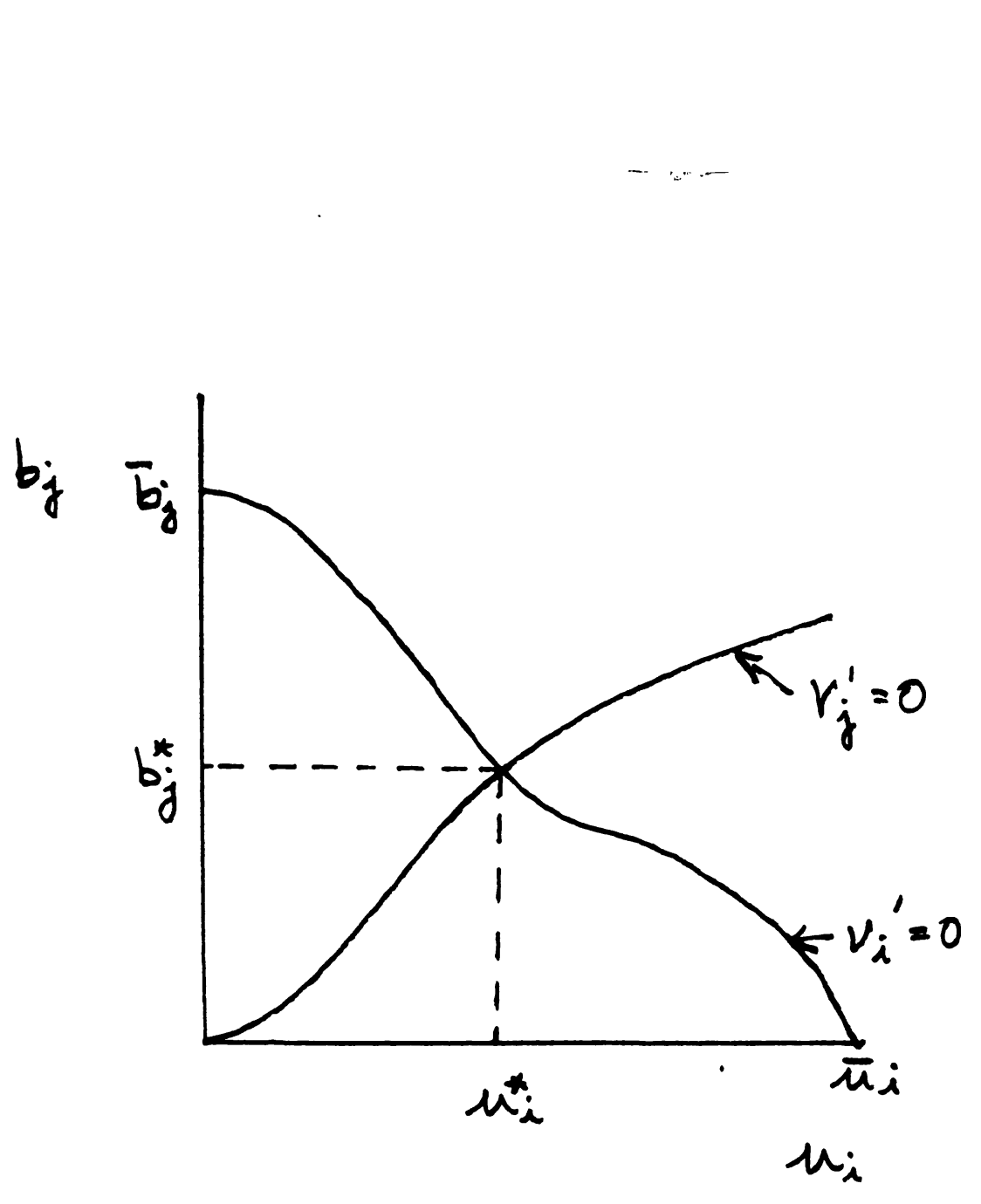

$\# 262$

\begin{abstract}
(n)
\end{abstract}


